\title{
Animation in User Interfaces Designed for Decision Support Systems: The Effects of Image Abstraction, Transition, and Interactivity on Decision Quality*
}

\author{
Cleotilde González \\ College of Engineering, Universidad de las Américas-Puebla, Puebla, México, \\ email: cleo@uldapvms.pue.udlap.mx
}

\section{George M. Kasper}

Department of Information Systems, School of Business, Virginia Commonwealth University, Richmond,VA23284-4000, email: kasper@acm.org

\begin{abstract}
This paper develops the idea of animation in user interfaces designed for decision support systems (DSS), proposes a framework to investigate the efficacy of animation in these interfaces, and reports on a study that examined the effects of properties of animation specified by the framework. Based on a review of selected background literature, principal properties affecting the efficacy of animation in user interfaces designed for DSS are identified and the effects on decision quality of three of these properties are hypothesized. To evaluate these hypotheses, data was collected in a laboratory experiment involving two different tasks. The results for both tasks indicate that animation in user interfaces designed for DSS should employ parallel as opposed to sequential navigation interactivity techniques. The decision quality of subjects that used a parallel navigation technique was significantly greater than that of those that used a sequential navigation interactivity technique. The results regarding the efficacy of image abstraction and transition effects varied by task. For one task, decision quality was significantly greater for subjects that used realistic as opposed to abstract images, but decision quality did not vary by transition effect. For the other task, decision quality was significantly greater for subjects that used gradual as compared to abrupt transition, but image abstraction had no effect on decision quality.
\end{abstract}

Subject Areas: Animation, Decision Support Systems, and Human-Computer Interface.

\section{INTRODUCTION}

Including animation in the design of user interfaces is a natural extension of graphical user interfaces. Moreover, animation seems particularly well suited for representing many real-world situations, and the conventional wisdom is that

*The Decision Sciences Institute would like to thank George Kasper for bearing the full cost of printing the color plates in this article. 
animation makes the user interface easier to use, more enjoyable, pleasurable, and understandable (Baecker \& Small, 1990; Chang \& Ungar, 1993; Robertson, Card, \& Mackinlay, 1993; SIGGRAPH 94, 1994). Despite this evidence, very little is known about the efficacy of animation for decision support. In fact, the efficacy of animation in user interfaces designed for decision support systems has not been studied directly.

The term decision support systems (DSS) is used here as defined by Scott Morton (1984) to include all forms of information systems and technologies designed to assist one or more users in making better decisions. Although the nature of the decision support provided by DSS range from passive to active (Henderson, 1987; Humphreys, 1986; Keen, 1987; Luconi, Malone, \& Scott Morton, 1986; Remus \& Kotteman, 1986) and from individual to group (DeSanctis \& Gallupe, 1987; Olson \& Olson, 1991), the goal in designing all decision support systems is to improve "decision quality" (Ginzberg \& Stohr, 1982, p. 12).

According to Daft (1991), a decision is "a choice made from among available alternatives" (p. 180). Choosing from among alternative courses of action lies at the heart of decision making (Payne, 1982). Decision quality is a measure of the goodness of this choice.

A user interface supports both the mechanics of the interaction and facilitates the broader notion of a dialogue between human and computer. As used here, a user interface is an "observable two-way exchange of symbols and actions between human and computer" (Hartson \& Hix, 1989, p. 8). In this way, the study of animation in user interfaces emphasizes the symbols and actions of images, the effects of images and images in action, and the user's actions and reactions to these images and their actions.

In the film industry, animation is defined as movement that brings characters to life (Solomon, 1983). In psychology, animation has been referred to as "apparent movement which is actually a series of still pictures" (Goldstein, 1989, p. 277). In education, animation is "a series of rapidly changing computer screen displays that represent the illusion of movement" (Rieber \& Hannafin, 1988, p. 78). In the human-computer interface literature, animation is a "sequence of static images changing rapidly enough to create the illusion of a continuously changing picture" (Baecker \& Small, 1990, p. 252). Some writers contend that animation must create the illusion of movement (Baecker \& Small; Keller \& Keller, 1993; Park \& Hopkins, 1992), others argue that animation includes change such as zooming, dissolving, fading, coloration, shading, and other transition and alteration effects (Magnenat-Thalmann \& Thalmann, 1985). For some, animation is simply another way of displaying images (Palmiter, Elkerton, \& Baggett, 1991; Rieber, Boyce, \& Assad, 1990); others contend that the user interface should be designed to support interactivity (Ginzberg \& Stohr, 1982) so that the images of animation change in ways guided by user actions (Robertson et al., 1993).

It is clear that animation can engage and entertain. Its role in user interfaces designed for DSS, however, is only beginning to be considered and the limited evidence is anecdotal. For the purposes of this study, animation in user interfaces designed for DSS is defined as images presented dynamically that change, guided by the user, in ways that improve decision quality. "Images presented dynamically that change" defines animation in user interfaces designed for DSS as consisting 
of different images presented in some series, one at a time. That these images are different in ways that "improve decision quality" defines the change as purposeful and consistent with the performance goal of DSS. That the "change" is also "guided by the user" highlights the directive role played by the user in DSS and the two-way exchange of symbols and actions that defines dialogue in humancomputer interfaces. This definition combines the principal notions of animation, DSS, and human-computer dialogue design.

This paper develops a research framework to evaluate the efficacy of animation in user interfaces designed for DSS and reports on a study that investigated the effectiveness of several of the components proposed in the framework. Specifically, the effects on decision quality of different animation symbols (image abstraction) and actions (transition and interactivity) were investigated in a laboratory study. The results indicate that the design of image abstraction, transition, and navigation interactivity affect decision quality.

Based on a review of selected background literature, properties affecting the efficacy of animation in user interfaces designed for DSS are developed below. Next, a study intended to compare the performance of subjects using different designs of animation in two different decision tasks is described. This is followed by a presentation of the data analysis and results. The results are then discussed. The paper ends with a summary of the findings and concluding remarks.

\section{BACKGROUND}

Even though we navigate daily through a perceptual world of three spatial dimensions and reason occasionally about higher dimensional arenas . . . the world portrayed on our information displays is caught up in the two-dimensionality of the endless flatlands of paper and video screen .... Escaping this flatland is the essential task of envisioning information-for all the interesting worlds...that we seek to understand are inevitably and happily multivariate in nature. (Tufte, 1990 , p. 12, italics in original)

Converting the four-dimensional reality of time and three-dimensional space into little marks on a two-dimensional screen is the essential dilemma of user interface design (Tufte, 1990). "One day this (conversion) will be accomplished using extremely high-resolution screens that combine slightly abstracted, dynamic, and animated images" (Tufte, 1990, p. 119, parenthetic and italics added). Effective animation depicts the four-dimensional reality of time and three-dimensional space in two dimensions by creating the illusions of depth and change over time.

Attempts to escape the flatland of paper and screen are chronicled by Tufte (1990) and include the pop-up models used in a 1570 edition of Euclid's book Elements to explain solid geometry. In a more recent example, two Connecticut teenagers, using software that allowed them to draw and redraw lines, solved the regular partitioning problem posited by Euclid some 2300 years ago: Given a line of any length, devise a universal geometric method for subdividing it into any number of equal parts (The Wall Street Journal, 1996). Another example, and one that makes clear use of change, is the computer animation created by the Geometry 
Center at the University of Minnesota illustrating the 1957 mathematical discovery of how one can turn the surface of a sphere inside out without making a hole (Outside In, 1994). In terms of decision making, many management decisions require identifying and assessing change, and in particular, change over time. Time is a dimension and change is a characteristic that animation is especially well suited to depict. Because of this, animation seems well suited to supporting many management decisions. Animation provides the designer of user interfaces for DSS with a tool to reduce the four-dimensional reality of time and three-dimensional space into the two dimensions of the display screen.

The basic unit of animation is the image. Composed of elemental symbols and their spatial orientation (Johnson-Laird, 1981), an image can be designed to be overlooked and unnoticed or to capture and maintain an observer's attention (Hochberg \& Brooks, 1978; Treisman \& Souther, 1985; Wickens, 1992; Woods, 1984). Attributes of elemental symbols include abstraction, color, form, and texture; examples of spatial orientation attributes are spatial proximity, similarity, closure, continuation, and depth cues (Finkel \& Sajda, 1994; Hochberg, 1986; Kosslyn, 1985; Marr, 1982; Treisman \& Souther). Using these attributes, an image can inform by what it abstracts, highlights, and mutes, capturing attention and reducing information overload where appropriate.

In addition to an image's elemental symbols and their spacial orientation, equally important considerations in animation are the design of transition and alteration effects. Transition and alteration effects mark or mitigate change between and within segments of images, respectively, by either accentuating or making the change "transparent" to the viewer. Transition effects include dissolving and fading. Alteration effects include coloration, texturing, and morphing.

In summary, the basic unit of animation, the image, can be designed to inform by accentuating or muting its elemental symbols and their spatial orientation and through transition and alteration effects within and between collections of images, respectively. The power of animation in interfaces designed for DSS may lie in its potential to highlight informative change and to mute uninformative change within and between images.

The techniques of animation are divided into so-called classical and, more recently, real-time techniques (Magnenat-Thalmann \& Thalmann, 1985). Classical techniques, founded on the methods developed to produce cartoons, are oriented towards the production of lifelike figures for the purpose of entertaining a passive viewer. Classical techniques focus on developing a set of images that are later presented in a given sequence and rate. Two issues are central to this purpose: smoothness and simplicity (Halas, 1990). Simplicity refers to the parsimonious nature of the images, the degree to which the image has abstracted the essentials of a situation. Smoothness refers to the transition and alteration effects that maintain the dynamics of continuous change.

Real-time techniques are intended to provide a level of interactivity needed to support a two-way exchange of images (symbols) and actions to sustain a human-computer dialogue. For this exchange to be directed by the user at a "natural" pace, the system must be responsive. To produce images dynamically and at rates that maintain responsiveness has meant that real-time animation has focused 
on designing hardware and software techniques that can deal effectively with the trade-off between response time and interactivity (Robertson et al., 1993).

Interactivity, the focus of real-time based animation, is not found in systems developed using classical techniques. Moreover, neither classical nor real-time techniques consider decision quality as a performance goal. The effects on decision quality of image simplicity (abstraction), the smoothness of images in action (transition and alteration), and the nature of human-computer interaction (interactivity) must be explicitly considered if animation in user interfaces designed for DSS is to be effective. Each of these are included in the framework developed below.

\section{A FRAMEWORK FOR STUDYING ANIMATION IN USER INTERFACES DESIGNED FOR DSS}

Before the effects of animation on decision quality can be considered, some framework is needed to guide the research. Models have been proposed for animation using either real-time or classical animation techniques (Palmiter, 1993; Robertson, Card, \& Mackinlay, 1989), but none of these consider the effects of animation on decision quality. Likewise, several models have been proposed to describe different aspects of human-computer interaction (Shneiderman, 1992). Perhaps the best known of these models is the goals, operators, methods, and selection rules (GOMS) model proposed by Card, Moran, and Newell (1983). GOMS postulates that users formulate goals that are achieved using methods, procedures, and technologies defined by the design of the system. Methods are in turn chosen using selection rules that are formulated based on the user's abilities, expertise, and experiences. Operators are elementary perceptual, motor, and cognitive actions. Other models of human-computer interaction propose various combinations of goals, perception, cognition, symbols, actions, technologies, task, and user characteristics (Shneiderman).

Design is prescriptive and goal oriented (Walls, Widmeyer, \& El Sawy, 1992). It specifies the goal(s), properties (operators and methods), and (selection) rules and structures needed for these properties to achieve the goal. The goal, properties, and hypothesized selection rules for choosing among the properties of animation to achieve the goal of animation in user interfaces designed for DSS are introduced and developed below.

\section{The Goal of Animation in User Interfaces Designed for DSS}

The goal of animation in user interfaces designed for DSS is to improve decision quality. To achieve this goal requires combining the simplicity and smoothness of classical animation technology and the interactivity of real-time systems. Simplicity addresses the content of an image, its elemental symbols and their spatial orientation; smoothness is a result of transition and alteration effects; and interactivity adds the responsiveness and user controllability needed for DSS. Simplicity, smoothness, and interactivity define properties of animation in user interfaces designed for DSS, and through the process of design, can be specified so that decision quality is improved. 


\section{Properties of Animation in User Interfaces Designed for DSS}

DSS integrates user, task, and information (in this case animation) technologies into a synergistic unit to improve decision quality. The interplay among user, task, and information technologies is the foundation for DSS and is a well-known triad in the information systems literature (Mason \& Mitroff, 1973; Newell \& Simon, 1972). Based on this foundation and the literature discussed above, a research framework for investigating the interplay among user, task, and animation technologies in user interfaces designed for DSS is proposed in Figure 1.

Selected instantiations of Task, User, and Animation believed to be particularly relevant to DSS are identified in Figure 1. The figure also suggests operators acting on Task, User, and/or Animation. Identifying (often empirically) the most effective combinations of these properties (i.e., the selection rules) is a key to effective design.

\section{Animation}

At the center of Figure 1 is Animation. The classical property of simplicity is instantiated as image abstraction. Image abstraction ranges from low, realistic images, to high, abstract images, depending upon how closely the symbols in the image resemble real-world objects (Deregowski, 1990; Hochberg, 1986). Images near the realistic end of this continuum offer the eye the same pattern of light as that of the real-world scene. Conversely, images near the high end of the abstraction continuum bear little resemblance to reality or real-world objects (Krampen, 1990). Abstract images often appear as line drawings and geometric shapes, whereas photographs of real-world objects are considered realistic images (Deregowski; Espe, 1990; Paivio, 1971).

Conventional wisdom is that abstract images are parsimonious and therefore effective conveyors of information. Abstraction, however, always runs the risk of going too far, removing information and adversely affecting decision quality. Moreover, abstract images can be used to depict both real and imaginary worlds whereas realistic images can only depict "real" objects and actions.

Animation in Figure 1 includes the classical notion of smoothness in the forms of Transition and Alteration. Transition and Alteration manipulate pictorial and spatial attributes of an image so as to optimize the user's attention level and reception to the information displayed. Theories of visual perception and cognition agree that gradual, progressive changes between visual patterns are needed to produce smooth, actively changing stimuli (Gibson, 1979; Hochberg \& Brooks, 1978; Woods, 1984). Alteration defines differences in consecutive images within a series (i.e., changes such as coloration and texturing that instantiate consecutive images of the animation) (Rieber \& Hannafin, 1988; Stasko, 1993; Treisman \& Souther, 1985). Transition specifies changes between major scenes (e.g., dissolving, fading, morphing, etc.) (Baecker \& Small, 1990; Chang \& Ungar, 1993).

Another instantiation of animation in Figure 1 is Interactivity. Interactivity ranges from the one-way to the two-way exchange of images and actions (Ginzberg \& Stohr, 1982). In one-way interactivity, the exchange of information is in only one direction. Animation based on classical techniques, typified by the motion picture, is an example of one-way interactivity. In one-way interactivity, the user 
Figure 1: A framework for studying animation in user interfaces designed for DSS.

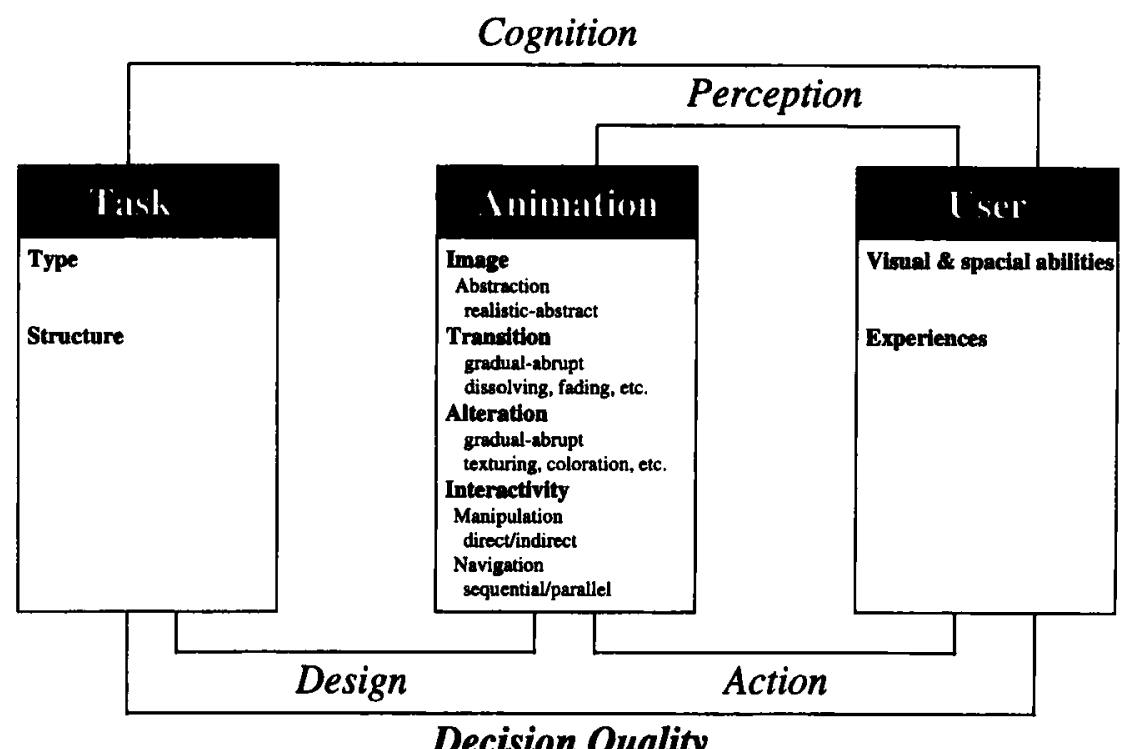

takes the passive role of simply responding to the actions of the system (Keen, 1987). In contrast, the two-way interactivity of human-computer dialogue requires the exchange of information. In two-way interactivity, the user views and responds to the animation and the animation "views" and responds to the user's directives (Hollnagel \& Woods, 1983). Because of this, two-way interactivity requires the responsiveness of real-time systems (Badler, Phillips, \& Webber, 1993; Magnenat-Thalmann \& Thalmann, 1985). Two-way interactivity requires systems that can respond by producing images at speeds such that they can be displayed at a rate approaching 24 frames per second, the current motion picture standard (Halas, 1990; Robertson et al., 1993).

It is generally believed that two-way interactivity engages the user and results in improved decision quality (Ginzberg \& Stohr, 1982). Two-way interactivity, however, would be counterproductive if it reduced decision quality, perhaps by imposing an overhead that increased the user's cognitive workload (Benbasat \& Todd, 1993; Davis \& Bostrom, 1993; Hale \& Kasper, 1989; Palmiter et al., 1991 ; Rieber \& Hannafin, 1988; Robertson et al., 1989).

As identified in Figure 1, Interactivity for animation in user interfaces designed for DSS combines the properties of manipulation and navigation. Manipulation can be either direct or indirect. As the name implies, direct manipulation involves the direct control of a displayed symbol (i.e., grasping, moving, rotating it, etc.) (Gobbetti, Balaguer, \& Thalmann, 1993; Isdale, 1993). In contrast, indirect manipulation utilizes some secondary means, such as commands, to apply actions to the elemental symbols of an image. 
The second form of Interactivity identified in Figure 1 is navigation. Navigation is either parallel or sequential. In parallel navigation, images can be selected in any order; whereas in sequential navigation, images are displayed in a specific sequence (Ahlberg \& Shneiderman, 1994; Thuring, Hannemann, \& Haake, 1995). Sequential navigation allows the user to navigate forward and backward in a fixed order from one end of a series of images to the other. Parallel navigation allows the user to go either forward or backward as desired from any point in a series of images. Parallel navigation may be better for DSS because it imposes less of an order restriction than does sequential navigation. On the other hand, sequential navigation is easier to operate and may be less cognitively taxing.

\section{User}

The user is shown on the right side of Figure 1. The user's ability to generate an appropriate mental model depends upon the processes of perception and cognition. Visual perception is determined by experiential information and spatial and visual abilities (Anderson, 1990; Hochberg, 1978; Kaufmann, 1980, 1985). Perception is shown at the top of Figure 1 as connecting the properties (images, transition and alterations, and interactivity) of animation and the user's visual and spatial abilities and experiential information. The user's experience with both the task and the form of the presentation are considered major determinants of human performance and decision quality (Anderson, 1990; Jarvenpaa \& Dickson, 1988; Kaufmann; Palmiter et al., 1991; Wickens, 1987; Woods, 1984; Rouse \& Morris, 1986).

Users differ in their visual and visualizing abilities and therefore perceive and perform visual tasks differently (Anderson, 1990; MacLeod, Hunt, \& Matthews, 1978). Users with high visual and spatial abilities develop more accurate visualizations when the information is depicted using images than do those with poor visual and spatial abilities (Kaufmann, 1980, 1985; Paivio, 1971; Rouse \& Morris, 1986; Simon, 1975). Users with high visual abilities seem to perform better in tasks that involve spatial orientation than do users with poor visual ability (Just \& Carpenter, 1985). This literature suggests that the user's visual and visualizing abilities may play important roles in determining the efficacy of animation in user interfaces designed for DSS.

In addition to perception, Cognition is a determinant of decision quality (Gillan \& Cooke, 1994; Hochberg, 1978; Hochberg \& Brooks, 1978; Treisman \& Souther, 1985; Wickens, 1987, 1992; Woods, 1984). Experiences influence cognition, and experiences in the task domain and with animation technologies would be expected to influence the efficacy of animation in user interfaces designed for DSS. Collectively, the user's visual and visualizing abilities, and experiences in the task domain and animation technologies should all be considered when investigating the efficacy of animation in user interfaces designed for DSS.

As Figure 1 indicates, the processes of Cognition and Action link Task and User, and User and Animation, respectively. Shown near the bottom of Figure 1, the User interacts with Animation through Action. Because the user seeks to better understand the task through the animation, Cognition is shown as linking User and Task (at the top of Figure 1). Likewise, Decision Quality reflects the quality of the 
Figure 2a: Example of HomeD task, realistic image, and parallel navigation interactivity treatment.

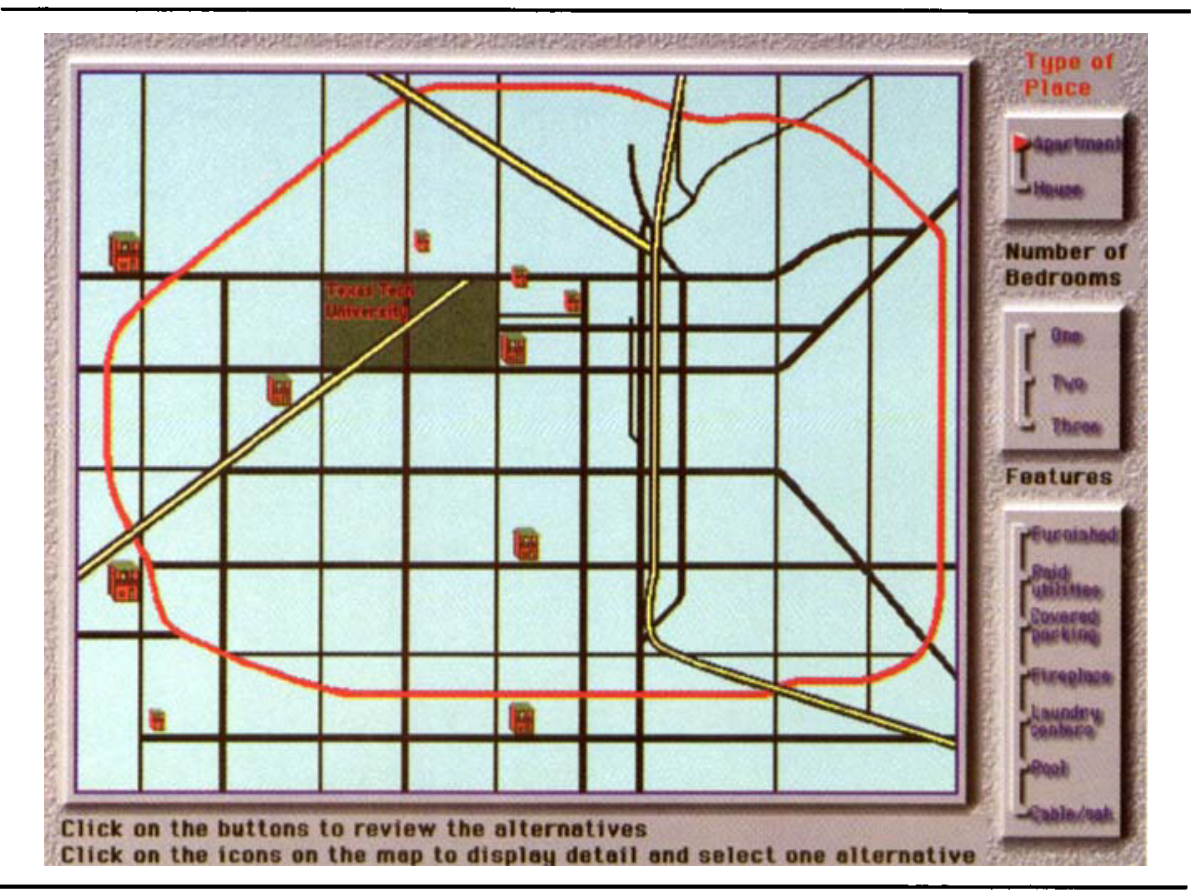

Figure 2b: Example of HomeD task, abstract image, and sequential navigation interactivity treatment.

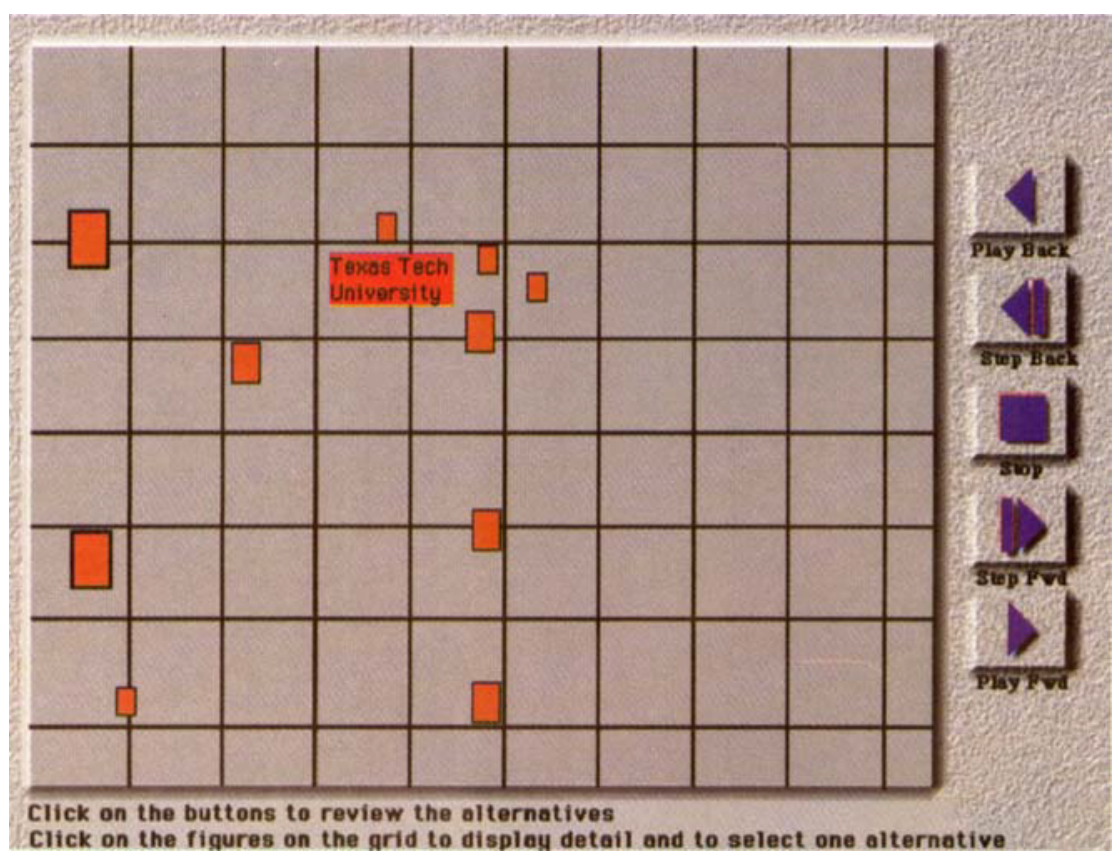


Figure 3a: Example of B\&B task, realistic image, and sequential navigation interactivity treatment.

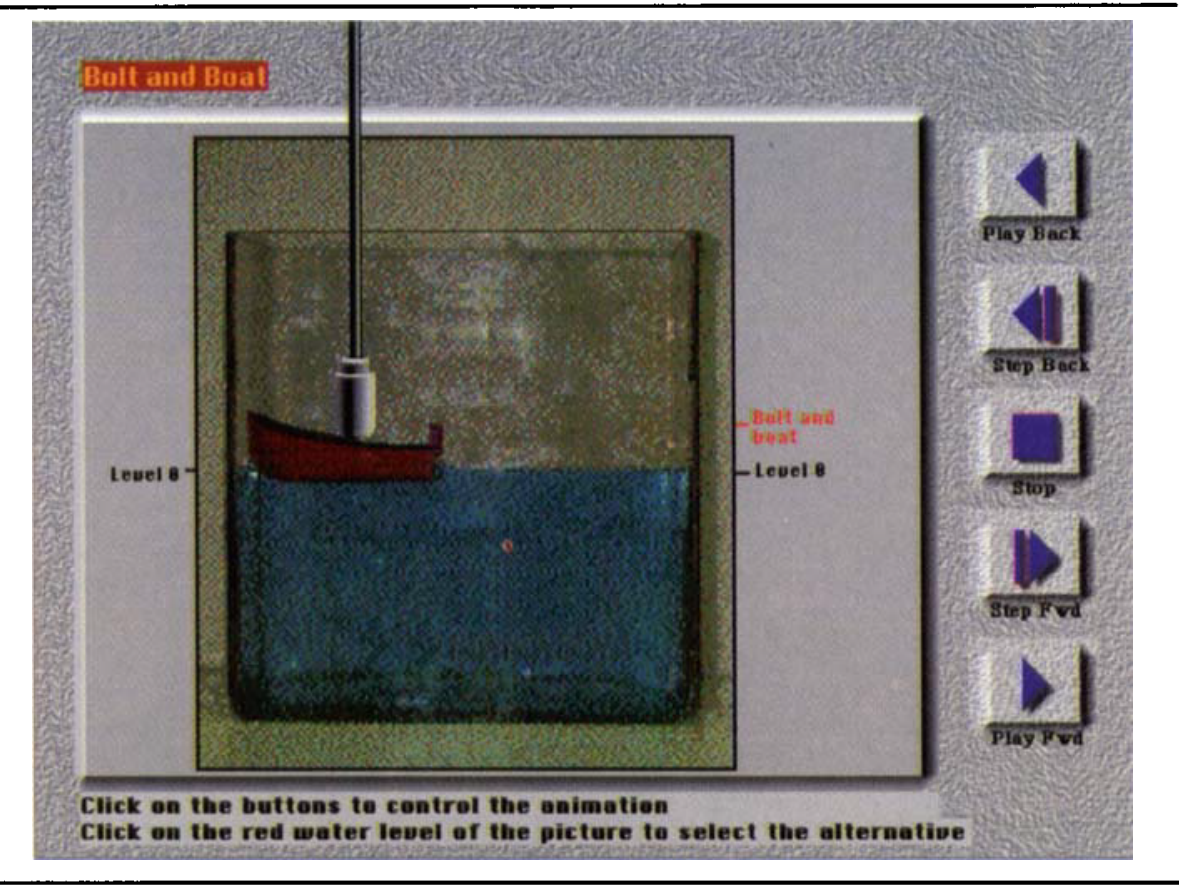

Figure 3b: Example of B\&B task, abstract image, and parallel navigation interactivity treatment.

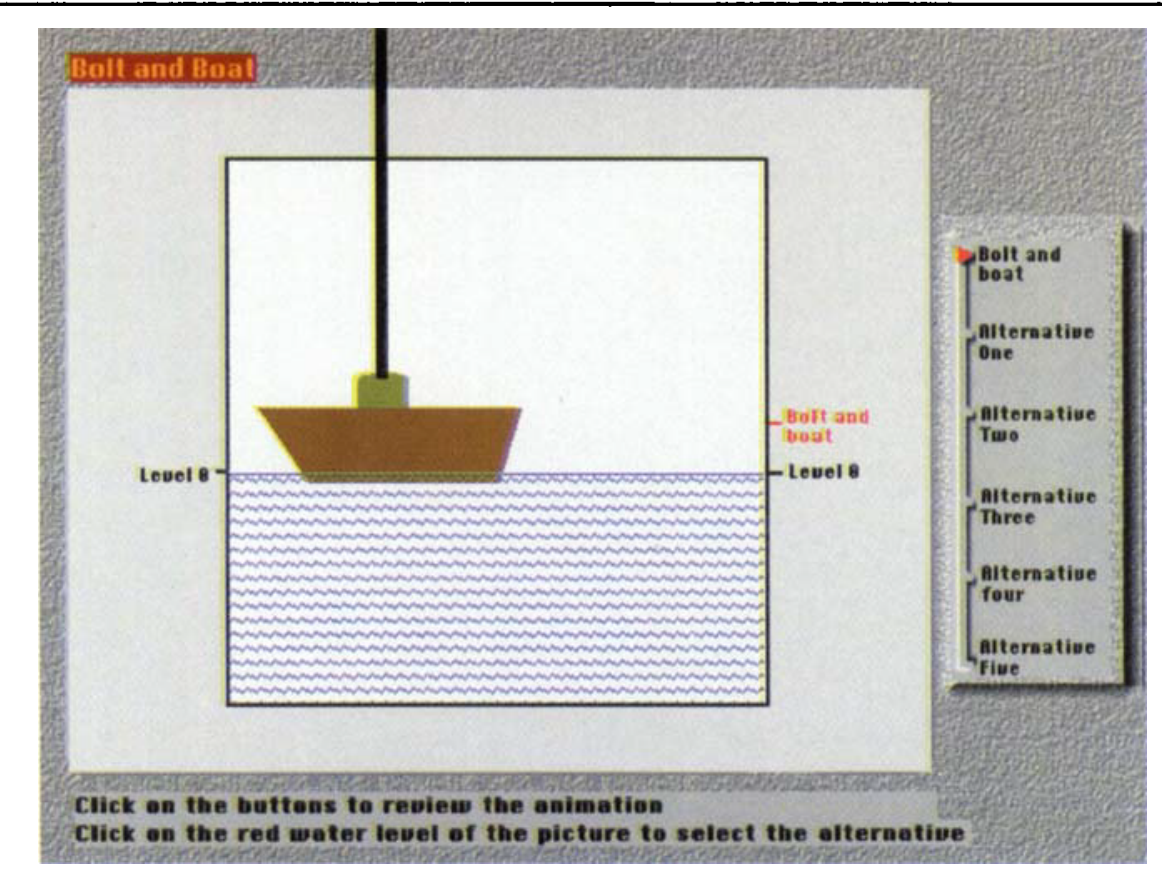


user's decisions in relation to the task and therefore, Decision Quality is shown as a relationship between User and Task (at the bottom of Figure 1).

\section{Task}

The third property shown in Figure 1 is Task. The instantiation of Task includes type and structure. In terms of task type, some tasks are inherently visual and dynamic and may be more effectively depicted using animation than are tasks that are static and linguistic (Kaufmann, 1980, 1985). Likewise, problem structure is well known in the decision-making and DSS literature as a determinant of decision quality (Ginzberg \& Stohr, 1982; Gorry \& Scott Morton, 1971; Simon, 1960). Decisions are structured to the extent that they are repetitive and routine, to the extent that a definite procedure has been worked out for handling them so that they don't have to be treated de novo each time they occur (Simon, 1960). Decisions with little or no structure are novel and lack procedures to deal with the situation (Simon, 1960). In structured problems, much of the problem solving can be automated, whereas problems requiring a combination of judgment and automation are known as "semistructured" problems (Keen \& Scott Morton, 1978). Unstructured problems rely on judgment alone.

Design is shown at the bottom of Figure 1 as linking Task and Animation. Good design produces useful artifacts. Design is the process of developing an architecture to build an artifact that satisfies requirements. Useful artifacts result from an understanding of requirements and a translation of requirements into an architecture that, when implemented and used, achieves the performance goal (Walls et al., 1992). Defining requirements is considered fundamental to all computer science (Newell \& Simon, 1976) and is a well-known determinant of effective DSS design (Sprague \& Carlson, 1982, p. 96). In the case of animation in user interfaces designed for DSS, the goal of improved decision quality dictates the design of the animation technologies used to build the artifact.

In summary, the goal of animation in user interfaces designed for DSS is to improve decision quality in the task domain. The user perceives (perception) and acts (action) on the animation artifact in an effort to understand (cognition) the task domain. Decision quality is a measure of the efficacy of the design of the animation artifact in relation to the user's abilities and experiences in the task requirements.

\section{Hypotheses}

If a model is to be useful as a scientific tool, it must be subject to refutation. The framework developed above and shown in Figure 1 suggests several research questions and hypotheses. Focusing on the effects of animation technologies on decision quality, three hypotheses are posited. Beginning with image abstraction, realistic images are believed to be cognitively and perceptually less demanding, making them simpler to comprehend, easier to use, and easier to interpret compared to abstract images (Anderson, 1990; Deregowski, 1990; Erickson, 1990; Espe, 1990; Gibson, 1979; Hochberg, 1978; Vaananen \& Shmidt, 1994). The effect of image abstraction on decision quality, however, is unknown. Based on this, it is hypothesized that: 
H1: Animation using realistic images results in better decision quality than animation using abstract images.

The literature on classical animation techniques indicates that gradual transition effects focus attention, increasing the user's ability to locate important data, thereby decreasing the mental workload (Norman, 1986; Wickens, 1992; Woods, 1984). Whether this improves decision quality, however, is unclear. Based on this and Figure 1, it is hypothesized that:

$\mathrm{H} 2$ : Animation using gradual transitions results in better decision quality than animation using abrupt transitions.

The two common types of navigation interactivity identified earlier were parallel and sequential. Parallel navigation interactivity imposes less structure than sequential navigation interactivity, making it a more controllable decision support tool. On the other hand, sequential navigation interactivity may make decision making easier and less cognitively taxing precisely because it imposes more structure (Ginzberg \& Stohr, 1982). A formal statement of this hypothesis is:

H3: Animation using parallel navigation interactivity results in better decision quality than animation using sequential navigation interactivity.

These hypotheses are intended to be neither complete nor exhaustive. The universe of discourse on animation in user interfaces designed for DSS is very broad. These hypotheses simply give an indication of the questions suggested by the framework depicted in Figure 1. These hypotheses do, however, highlight improved decision quality as the goal of animation in user interfaces designed for DSS.

\section{EXPERIMENTAL DESIGN AND METHODOLOGY}

The hypotheses developed above were investigated in a laboratory experiment using a 2 (image abstraction) by 2 (transition) by 2 (navigation interactivity) experimental design. The three treatment factors resulted in eight treatment combinations. Responding to the hypotheses, the eight treatment combinations varied by type of image abstraction (realistic or abstract), type of transition (gradual or abrupt), and type of navigation interactivity (parallel or sequential). To increase the applicability of the results, this experimental design was applied to two different task domains in counterbalanced order. One task domain involved the relatively familiar, wellstructured task of choosing the "best" place to live from a visually depicted set of attributes taken from a multiple-listing real estate guide. The second task placed the subject in the less familiar and less structured domain of fluid dynamics, judging the change in the level of water resulting from submerging an object in water. In both cases, decision quality was defined as the relationship between the choice made by the subject from among the available alternatives and the best alternative.

In addition to the direct control of variability in experimental error provided by the treatment conditions, indirect or statistical control was achieved by measuring the user's experiences and visualizing ability. Likewise, the user's decision 
time was recorded because of the potential trade-off between decision time and decision quality (Sperling \& Dosher, 1986). These concomitant variates were used as covariates in the data analysis (Winer, 1971). In summary, the research model for this study was:

Decision quality $_{(\text {Task })}=f$ (Animation [image abstraction, transition, navigation interactivity],

User [visualizing ability, experience (Task), other relevant experiences, decision time (Task) $_{\text {), }}$,

where decision quality was measured for each of two tasks for each user, and the user's task experience and task decision time were recorded as was the user's experiences with relevant technologies.

\section{Task}

Two different task domains were constructed for this study. One task, known as the Home Directory, or HomeD for short, involved the familiar problem of choosing the "best" place to rent from among a set of possible alternatives. The second task, known as the Bolt and Boat, or B\&B for short, was a less well-known fluid dynamics problem. In selecting these tasks several issues were considered. As suggested by Mennecke and Wheeler (1995), these included: the appropriateness and attractiveness of the tasks to the subjects, the availability of procedures to represent and implement the tasks visually, the likelihood that the subjects would understand the objective of the tasks, and the means to measure and evaluate the subject's decision quality.

The HomeD task placed the subject in the hypothetical situation of finding a place to rent (houses or apartment) in a midsize city, well known to the subjects, in the Southwest United States. Evaluating 10 fixed nonprioritized visual attributes used to describe each place to rent, subjects selected from among 20 alternatives the one that "most closely" matched the set of attributes defining the "best" place to live. Attributes for this best place were given to the subject at the beginning of the task. No single choice matched all the attributes of this best place to live. The displayed image showed subjects a map of the city with icons indicating the location of the available properties. By directly pointing and clicking on a particular property, a picture of the property and a listing of its attributes were displayed in a window. Alternatives and their attributes were taken from the multiple-listing real estate guide for the city. The attributes were: number of bedrooms, furnished, utilities, covered parking, fireplace, laundry facilities, pool, cable TV, location, and cost. The HomeD task was selected for this study because it is an application that has been touted as an exemplary use of computer visualization (Ahlberg \& Shneiderman, 1994) and because it is similar to that used in other studies (e.g., Todd \& Benbasat, 1994a, 1994b).

The $B \& B$ task required the subject to choose the alternative that best described the change in fluid level resulting from placing a bolt in a bucket of water. Subjects were shown the side view of a transparent bucket approximately three-quarters full of water. A boat was afloat on the water and a bolt was suspended over the boat by a wire. The bolt was lowered into the boat and the subject 
was shown an accurate representation of the resulting rise in the level of the water. The bolt was then lifted from the boat and the water level and boat returned to their starting points. The bolt was then moved so that it was suspended over the water and it was dropped into the water, sinking to the bottom of the bucket. The subject was then instructed to select from among five alternatives the one that best described the level of the water with the bolt lying at the bottom of the bucket of water. Following the laws of fluid dynamics, only one alternative is correct and the others vary in correctness as defined in Kaiser, Proffitt, Whelan, and Hecht (1992).

As in the HomeD task, the subject could consider a B\&B alternative by pointing and clicking on it. The selected alternative was then displayed in a window on the screen. The window showed a picture of the level of the water and stated the specific displacement in millimeters and inches resulting from the alternative being considered by the subject. The subject could then choose the alternative just viewed or go on and consider another alternative. The B\&B task domain was selected because it has been used in past research and because it represents a truly dynamic, perceptually and cognitively challenging situation for subjects (Kaiser et al., 1992).

\section{Animation}

According to the experimental design, eight different combinations of treatment factors (image abstraction, transition, and navigation interactivity) were constructed for each of the two task domains. These were built using Macromedia Director 4.0 on a PowerMac. The run-time version of each combination of manipulations was embedded in an application that controlled the execution of the task, computed and recorded the decision quality of the alternative selected by the subject, and recorded the subject's decision time (the elapsed time taken by the subject to select an alternative). Because it has been argued that sound improves user operation and understanding of interface animation (Clanton \& Young, 1994), the same sound effects (e.g., mouse clicks and tones) were used in all manipulations. Finally, execution time was normed so that all HomeD and B\&B manipulations took the same amount of time to execute, given identical user actions.

Following guidelines suggested by Hix and Hartson (1993), the screen layout for all manipulations was divided into three windows: the image window, the interactivity window, and the message window. The image window, approximately $80 \%$ of the screen, displayed either realistic or abstract images, as dictated by the experimental design, of either the HomeD or the B\&B alternatives. The interactivity window, about $18 \%$ of the screen, displayed the navigational icons for the implementation of either sequential or parallel navigation interactivity. The balance of the screen, the message window, provided the user with instructions that were the same for all treatment combinations. By pointing and clicking on an alternative, a pop-up window allowed the user to view a specific choice. This provided a form of direct manipulation interactivity consistent with that found in Ahlberg and Shneiderman (1994).

According to Bertin (1983) and Dent (1985), a map is a realistic image of location information that is geographic in nature. Based on this, a city map was scanned and edited to form the basis for the HomeD realistic image. As the example 
in Figure 2a shows, somewhat embellished geometric shapes were superimposed on the scanned map to indicate the location of places to rent. These shapes, triangles for houses (not shown) and squares for apartments, varied in size to indicate the number of bedrooms (small $=1$ bedroom, medium $=2$ bedrooms, large $=3$ bedrooms). In the abstract version of the HomeD task, Figure $2 b$, a starfield display, a two-dimensional scatterplot often used to display geographic information (Ahlberg \& Shneiderman, 1994), was used to depict the city and to locate places to rent. Simple geometric shapes, again triangles for houses and squares for apartments, were used to indicate the location of places to rent. All other aspects of both the realistic and abstract images for the HomeD task were the same.

The realistic image for the B\&B task, shown in Figure 3a, was created by digitizing a picture taken of a model constructed for this purpose. The model was constructed using a transparent glass container and a toy boat. A picture of this model was taken with a digital camera and imported into Macromedia Director. Micromedia MacroModel was used to construct the bolt. For the abstract image, Figure 3b, a square represented the container, a trapezoid represented the boat, and a rectangle represented the bolt.

Transitions were either gradual or abrupt. Gradual transitions were implemented by making smooth transitions between consecutive frames and by providing transition effects between displayed alternatives. The dissolve (bits fast) effect initiated the fade-out of an image superimposed on the fade-in of the next image. In the gradual transition treatment level for the HomeD task, icons representing the alternative places to rent appeared one at a time; in the abrupt level, no transition effects were used with responses appearing all at once. For the B\&B task, gradual transition was implemented by depicting small changes in the positioning of the boat, bolt, and water on consecutive images. In the abrupt transition, again, no transition effects were used, resulting in what appeared to be instantaneous changes between scenes. For example, in the B\&B task, abrupt transition showed the bolt suspended out of the water; the next frame showed the bolt right above the water; and in the next frame the bolt was shown at the bottom of the bucket.

Navigation interactivity was implemented as either parallel or sequential. These were designed based on those recommended by Ahlberg and Shneiderman, (1994) and are shown in the interactivity windows of the displays in Figures 2a through $3 \mathrm{~b}$. Implementation of parallel navigation interactivity is shown in the interactivity windows in Figures $2 \mathrm{a}$ and $3 \mathrm{~b}$. Implementation of sequential navigation interactivity is shown in the interactivity windows in Figures $2 b$ and $3 a$.

As shown, parallel navigation interactivity provided the user with control over the order in which the images in each series were presented. Buttons were used to run any segment of the animation in any order. For example, parallel navigation interactivity in the HomeD task (Figure 2a) allowed the user to choose the attribute and observe the alternatives or to choose the alternative and observe the attributes. Clicking on any button in the interactivity window at any time, the system would respond by showing the alternatives for the attribute or vice versa as directed by the user.

Sequential navigation interactivity, shown in Figures $2 b$ and $3 a$, provided the user with buttons to navigate through the animation only in predefined sequences. 
The buttons were those normally found in any sequential navigation device: play forward, step forward, stop, step backward, and play backward. The user clicked on any one of these buttons at any time, playing the animation, stepping through the images either forward or backward, or stopping on one image.

As mentioned earlier, the user could select a specific alternative by pointing and clicking on it. This caused a pop-up window to appear on the screen that displayed the selected alternative. In the case of the HomeD task, a picture of the place to rent was displayed along with a listing of attributes and their values. For the B\&B task, the window animated the scenario described by the selected alternative (e.g., one alternative animated the level of the fluid actually going down when the bolt was placed in the water). The user could then choose the displayed alternative or close the window and continue.

\section{User Subjects}

User subjects were recruited from undergraduate students in the College of Business Administration at Texas Tech University. Recruitment followed the guidelines of the American Psychological Association (1992). These guidelines require that all subjects participate voluntarily and receive course credit for their participation. Students were told that in order to participate they could not be color blind and needed to have some experience using a personal computer and mouse. The study was briefly described to the students, and those willing and able to participate were asked to write their names and telephone numbers on a recruitment form. In total, 100 students volunteered to participate in the study. These subjects were later contacted and scheduled to take the experiment.

No specific hypotheses were proposed regarding user characteristics. Data on user subjects was collected to provide statistical control increasing the precision of the experiment by reducing the experimental error (Winer, 1971). In accordance with the research model, measures of the subjects recorded in this study were task and technology experiences, visualizing ability, and decision time. The subject's visualizing ability and experiences were gathered by two post-experiment questionnaires. Visualizing ability was measured by the Vividness of Visual Imagery Questionnaire (VVIQ) as formulated by Marks (1973). The VVIQ is a measure of the quality of one's ability to visualize an object. Each question on the VVIQ has a rating from 1 (mental image is clear and vivid) to 5 (no mental image at all). Consisting of 16 questions, the VVIQ requires about 10 minutes to complete. Used in over 100 studies, reliability for the VVIQ is quite good, ranging from .85 to .94 (Marks, 1973, 1989; Richardson, 1994).

User experiences were measured using a questionnaire developed specifically for this study. Following Nielsen (1993), user experiences were measured along five dimensions: experience with computers in general, experience with each of the two tasks, and experiences with graphical interfaces and animationtype systems. Sixteen questions were developed to measure these dimensions. Factor analysis of the data collected from the subjects in this study resulted in five factors: user experience with computers in general, user experience in each of the two task domains of the study, and experiences using graphical interfaces and animation-type systems. Each of these factors had an eigenvalue greater than 1 and 
consisted of two or more questions. In total, these five factors explained $72 \%$ of the variance in the user-experiences data collected from the subjects in this study.

The final concomitant variate used in this study was decision time for each task. Decision time was recorded in seconds by the same software that presented the manipulations to the user and computed and recorded decision quality. Decision time was recorded because it has been suggested that the trade-off between decision time and decision quality be recognized in decision-making studies (Sperling \& Dosher, 1986). Before being used in this study, the user-experiences questionnaire, treatments, and procedures were previewed and revised based on several evaluations including the results of a pilot study.

\section{Dependent Variables}

The dependent variables for this study were decision quality for the HomeD and B \& B tasks. Decision quality was determined and recorded automatically by the manipulation software. Following Kaiser et al. (1992), decision quality was defined based on how close the alternative selected by the subject was to the correct or "best" alternative. Recall that only one best answer existed for each of the two tasks used in this study. For the HomeD task, decision quality was calculated by counting the number of attributes of the alternative selected by the subject that matched those of the hypothetical place defined as the best place to live. Decision quality for the HomeD task could range from 0 to 10 in increments of 1 . For the $\mathrm{B} \& \mathrm{~B}$ task, decision quality was also defined based on how close the alternative selected by the subject was to the correct alternative. Using scoring defined in Kaiser et al., the selected alternative resulted in a decision quality score ranging from 1 to 5 in increments of 1 .

\section{Procedure}

Subjects were scheduled to participate in the study in one-hour time intervals. The experiment was administered to subjects in groups of eight over five consecutive days. Subjects took from 30 to 40 minutes to complete all aspects of the experiment.

Subjects gathered in a study area outside a computer laboratory. Instructions were delivered to the subjects in both written and videotaped form. For each of the tasks, the instructions specified the objective of the task and that decision quality would be used to evaluate performance. The written and videotaped instructions also discussed and demonstrated how each system would look and operate. After reading the instructions and viewing the two-minute video, any questions the subjects had regarding the procedures and objectives of the study were answered. Next, subjects completed a consent form and started the laboratory work.

The computers used for the study were Power Macintoshes configured with a 13-inch color monitor and $8 \mathrm{MB}$ of RAM. Subjects entered the laboratory and were free to select any one of the eight machines. Going to each machine, one of the researchers entered an identification number for each subject. This named the files on which the subject's data was to be recorded and assigned a treatment regimen according to the experimental design and the first of two tasks the subject was to consider. Based on the identification numbers, both treatment levels and 
task order were randomly assigned so that the task was counterbalanced and the number of observations in each treatment cell was expected to be balanced.

Subjects donned headphones and began the computer program and first task. The computer program began with a Welcome screen. As directed, the subject began the program by clicking on a button at the lower right-hand corner of the Welcome screen. Once the subject completed the first task, the program displayed a screen indicating that the subject should proceed to the next task. The subject began the second task just as the first by clicking on a button at the lower righthand corner of the screen as directed. After choosing an answer to the second task, each subject completed the VVIQ and experience questionnaires. Each subject was then debriefed, thanked, and dismissed.

\section{DATA ANALYSIS AND RESULTS}

Of the 100 students who agreed to participate in the study, five failed to show up for the experiment, five did not follow the directions, and one declared himself to be colorblind. This resulted in a sample size of 89 . Of these 89 subjects, $65 \%$ were undergraduate seniors, $27 \%$ were juniors, and $90 \%$ were business majors. Thirtyeight percent of the subjects were female and four subjects $(4.5 \%)$ reported that their native language was something other than English.

All 89 subjects completed both the HomeD and the B\&B tasks in counterbalanced order but remained in the same treatment levels for both tasks. The counterbalancing of tasks provided a direct control for order, and the random assignment of subjects to order and treatment levels assured that the expected differences between grouping (order and treatment levels) was zero at the time of the randomization (Cohen \& Cohen, 1975). Forty-five subjects completed the HomeD and then the B\&B task; the remaining 44 subjects completed the tasks in the reverse order. Table 1 shows the means, number of observations, and standard deviations for the dependent variable (decision quality) by animation treatment level (image abstraction, transition, and navigation interactivity) for each task. The data show that subjects exposed to realistic images had higher average decision quality for both tasks than those exposed to abstract images. Likewise, subjects exposed to gradual transitions performed better on both tasks than those who viewed abrupt transitions. Finally, the subjects using parallel navigation interactivity performed better on both tasks than those using sequential navigation interactivity.

To assess the statistical significance of the differences in decision quality suggested by the means in Table 1, a two-step multivariate analysis of covariance was computed. The two-step procedure involved residualizing the decision quality data for each task by "removing" the effects of the covariates and then computing a multivariate analysis of variance (MANOVA) using these residuals as the dependent variables. This was done because two of the covariates, decision time and task experience, were task specific. Likewise, by design, the decision tasks differed, making repeated measures analysis inappropriate.

Multivariate analysis of covariance combines multiple regression analysis and MANOVA. Following Cohen and Cohen (1975, pp. 308-310), decision quality was residualized and a MANOVA was computed on these residuals. This 
Table 1: Decision quality means, standard deviations, and number of observations by treatment levels for the HomeD and B\&B Tasks.

\begin{tabular}{|c|c|c|c|c|c|c|}
\hline & & & \multicolumn{4}{|c|}{ Task } \\
\hline & & & \multicolumn{2}{|c|}{ HomeD $(N=89)$} & \multicolumn{2}{|c|}{$\mathrm{B} \& \mathrm{~B}(N=89)$} \\
\hline \multicolumn{3}{|c|}{ Animation Treatment Levels } & Mean & $S D$ & Mean & $S D$ \\
\hline \multirow[t]{2}{*}{ Image Abstraction } & abstract & $(n=44)$ & 5.93 & 1.68 & 3.31 & 1.06 \\
\hline & realistic & $(n=45)$ & 6.89 & 1.99 & 3.52 & 1.25 \\
\hline Transition \& & abrupt & $(n=42)$ & 6.26 & 1.93 & 3.05 & 1.25 \\
\hline Alteration & gradual & $(n=47)$ & 6.53 & 1.88 & 3.75 & 0.97 \\
\hline Direct Manipulation & sequential & $(n=42)$ & 5.74 & 1.74 & 3.12 & 1.11 \\
\hline Interactivity & parallel & $(n=47)$ & 7.00 & 1.84 & 3.68 & 1.14 \\
\hline
\end{tabular}

involved using multiple regression to "remove" the effects of the covariates from the dependent variable (decision quality) for each task. The residuals from these regressions were then used as the dependent variables in a MANOVA defined by the experimental design.

Regressing decision quality on the covariate measures (VVIQ, user experience with computers in general, experiences using graphical interfaces and animation-type systems, task experience, and decision time) for the HomeD task resulted in a significant reduction in the experimental error $\left(F_{(6,82)}=2.65, p \leq .021\right.$, $R^{2}=.16$ ), but decision time was the only covariate significant at the $\alpha \leq .05$ level $(\beta=.261, t=3.34, p \leq .002)$. Removing the effects of the respective covariates from decision quality for the $B \& B$ task produced insignificant results $\left(F_{(6,82)}=1.18, p \leq .324, R^{2}=.08\right)$. That the measures of the user (i.e., VVIQ, experience with computers in general, task experience, and experiences using graphical interfaces and animation-type systems) were not significant is consistent with the results reviewed in Huber (1983). The regression results of this study are not reported in more detail here because no specific hypotheses were proposed regarding these covariates and because, with the exception of decision time in the HomeD task, the results were insignificant.

Although very little of the experimental error was accounted for by the covariates, because decision time and task experience were task specific, a MANOVA was computed using the respective residuals of decision quality for each task following Cohen and Cohen (1975).Using this data, a MANOVA test criteria and exact $F$ statistic were computed for each hypothesis of no overall effect. Results of the Wilks' Lambda test for each hypothesis are presented in Table 2.

Based on the results shown in Table 2, the hypotheses of an overall image abstraction effect ( $\mathrm{H} 1)$ cannot be rejected; overall, animation using realistic images did result in better decision quality than animation using abstract images. These results also fail to reject $\mathrm{H} 2$; overall, subjects who viewed gradual transitions did have significantly higher decision quality than those who viewed abrupt transitions. Likewise, the MANOVA test criteria and exact $F$ statistic of the hypothesis for the overall navigation interactivity effect, $\mathrm{H} 3$, cannot be rejected, 
Table 2: MANOVA test criteria and exact $F$ statistics for the hypotheses of no overall effect.

\begin{tabular}{lccc}
\hline Hypotheses & Wilks' Lambda & $F_{(2,84)}$ & $p$ value \\
\hline H1 (image) & .882 & 5.63 & $.005^{*}$ \\
H2 (transition) & .884 & 5.49 & $.006^{*}$ \\
H3 (navigation interactivity) & .851 & 7.38 & $.001^{*}$ \\
\hline
\end{tabular}

${ }^{*} p \leq .05$

and it can be concluded that parallel navigation interactivity did result in better decision quality than sequential navigation interactivity.

To clarify the MANOVA results, analysis of variance (ANOVA) was computed for the HomeD and the B\&B residualized data separately. Presented in Table 3, these results clarify those of the MANOVA overall analysis. The ANOVA results show that decision quality for the HomeD task was affected significantly by both image abstraction and navigation interactivity, but transition did not affect decision quality. Subjects using realistic images had significantly higher decision quality than did those using abstract images. Again, $\mathrm{H} 1 \mathrm{cannot}$ be rejected; animation using realistic images did result in better decision quality than animation using abstract images for the HomeD task. Likewise, the results fail to reject $\mathrm{H3}$; parallel navigation interactivity resulted in better decision quality than sequential navigation interactivity for the HomeD task. The HomeD results for $\mathrm{H} 2$, however, vary from the MANOVA overall results; there was no significant difference in the decision quality of subjects who viewed gradual transitions compared with those who viewed abrupt transitions.

Similarly, the ANOVA results for the B\&B task vary from those of the HomeD task and the overall MANOVA. The data in Table 3 for the B\&B task show that both transition and navigation interactivity had significant effects on decision quality. Consistent with the MANOVA overall results and the HomeD findings, the data again fail to reject $\mathrm{H} 3$; subjects using parallel navigation interactivity had higher decision quality than those using sequential navigation interactivity. Consistent with the overall MANOVA results, but unlike the HomeD findings, $\mathrm{H} 2$ cannot be rejected; gradual transitions did result in better decision quality compared with abrupt transitions in the B\&B task. However, unlike both the HomeD and the MANOVA results, the $\mathrm{B} \& \mathrm{~B}$ data rejected $\mathrm{H1}$; the decision quality of subjects viewing realistic images was no higher than for those viewing the abstract images.

Collectively, $\mathrm{H} 3$ cannot be rejected; the results regarding interactivity are consistent. When employing animation in decision support systems, parallel navigation interactivity results in better decision quality than sequential navigation interactivity. The results for $\mathrm{H} 1$ and $\mathrm{H} 2$, however, are inconsistent. In the HomeD task, decision quality varied by image abstraction but not transition levels. In the B\&B task, the results were the opposite; decision quality varied by transition but not image abstraction levels. 
Table 3: Analysis of variance of decision quality (residuals) for the HomeD and B\&B Tasks.

a. ANOVA Results of Decision Quality (residuals) for the Home Directory (HomeD) Task

\begin{tabular}{lrrcc} 
Source & $d f$ & $\begin{array}{c}\text { Sum of } \\
\text { Squares }\end{array}$ & $F$ value & $p$ value \\
\hline Model & 3 & 52.61 & 7.05 & $.0003^{*}$ \\
Error & 85 & 211.36 & & \\
Corrected Total & 88 & 263.96 & & \\
\hline
\end{tabular}

$R^{2}=.20$

\begin{tabular}{lcrrr} 
Source & $d f$ & Type III SS & $F$ value & $p$ value \\
\hline Image & 1 & 27.66 & 11.12 & $.0013^{*}$ \\
Transition & 1 & 1.48 & 0.60 & .4424 \\
Navigation interactivity & 1 & 24.56 & 9.88 & $.0023^{*}$
\end{tabular}

${ }^{*} p \leq .05$

b. ANOVA Results of Decision Quality (residuals) for the Bolt and Boat (B\&B) Task

\begin{tabular}{lrrrr} 
Source & $d f$ & $\begin{array}{c}\text { Sum of } \\
\text { Squares }\end{array}$ & $F$ value & $p$ value \\
\hline Model & 3 & 17.20 & 5.35 & $.0020^{*}$ \\
Error & 85 & 91.06 & & \\
Corrected Total & 88 & 108.26 & & \\
\hline$R^{2}=.16$ & & &
\end{tabular}

\begin{tabular}{lcrrr} 
Source & $d f$ & Type III SS & $F$ value & $p$ value \\
\hline Image & 1 & .46 & 0.42 & .5167 \\
Transition & 1 & 11.44 & 10.69 & .0016 \\
Navigation interactivity & 1 & 5.97 & 5.57 & $.0205^{*}$
\end{tabular}

*p $\leq .05$

\section{DISCUSSION OF THE RESULTS}

The effective use of animation in user interfaces designed for DSS is just emerging as a topic of research and practice. The results of this study indicate that the efficacy of animation in user interfaces designed for DSS is in part dependent upon the design of the navigation interactivity. Specifically, the decision quality of subjects exposed to parallel navigation interactivity was greater than that of those exposed to sequential navigation interactivity for both tasks considered here. One reason for this result might be that parallel navigation interactivity provides the user with greater control over the presentation of information than sequential navigation interactivity. This reasoning is consistent with Ginzberg and Stohr's (1982) contention that "controllability," the degree to which the user directs the DSS, is central to the design of effective user interfaces for DSS. Moreover, previous research has demonstrated the importance of interactivity in human-computer 
interaction (Badler et al., 1993; Gobbetti et al., 1993; Jacob, Sibert, McFarlane, \& Mullen, 1994) and DSS (Ginzberg \& Stohr, 1982; Hale \& Kasper, 1989; Kasper, 1996), and the results of this study add to the generalizability of this overall finding by showing that interactivity is also important for effective animation in user interfaces designed for DSS. Finally, the significance of parallel interactivity justifies highlighting the directive role of the user in the definition posited earlier for animation in user interfaces designed for DSS: Images presented dynamically that change, guided by the user, in ways that improve decision quality.

In terms of image abstraction, the findings varied by task. In the HomeD task, subjects who used realistic images had significantly higher decision quality than those who viewed the abstract images; but in the B\&B task, no significant difference in decision quality was found between users of the abstract and realistic images. Recall that construction of the "realistic" and "abstract" images followed that suggested in the literature; that is, abstract images were constructed using geometric shapes and realistic images were photographs of "real-world" objects.

An examination of the objects depicted in the images seems to suggest an apparent explanation for these conflicting results. In the B\&B task, the objects (boat, bolt, bucket, water level, wire) are naturally geometric shapes. In this way, both the "realistic" and "abstract" images for the B\&B task (Figures 3a and 3b) are fundamentally geometric shapes, perhaps accounting for the result of no difference in decision quality. Unfortunately, the same argument can also be made for the HomeD images; but, in this case, the realistic images resulted in better decision quality than the abstract images. The actual layout of the city depicted in the HomeD image is a geometric grid, making the "realistic" image of the city (Figure $2 a$ ) inherently the same as the "abstract" image (Figure 2b). Nevertheless, subjects using the HomeD realistic images did outperform (had significantly higher decision quality) those viewing the abstract image, even though the presentation of specific alternatives was the same for both levels of abstraction.

One implication of these results is that image abstraction is a much more complex issue than whether geometric shapes or photographs are used to construct the images. The degree to which symbols abstract reality probably depends upon the reality being depicted. Comparing Figures $2 a$ with $2 b$ and $3 a$ with $3 b$ suggests that the difference between the two B\&B images (Figures $3 a$ and $3 b$ ) may be greater than the two HomeD images (Figures $2 a$ and $2 b$ ). However, in terms of decision quality, the statistical differences were the opposite: The difference in decision quality between the B\&B images was not significant while the HomeD images produced a statistically significant difference. The "abstract" version of the B\&B (Figure 2d), appears easier to view than the "realistic" version (Figure 2c), but there was no significant difference in decision quality. Likewise, a map such as the one photographed as the "realistic" image in the HomeD (Figure 2a) is an abstraction of reality and not an aerial photograph of the actual street layout of a locale. From the perspective of improving decision quality, perhaps image abstraction needs to be considered more along the lines of that used in abstracting text; that is, indicative, informative, and explicative abstracts (Cremmins, 1982). To the extent that this distinction is somewhat akin to that made between information and data, information systems researchers would seem particularly well suited to 
developing the notion of image abstraction from the perspective of improving decision quality.

Transition also produced somewhat mixed results. Gradual transition resulted in better decision quality in the B\&B task, but there was no statistically significant difference in decision quality between abrupt and gradual transition in the HomeD task. One possible explanation might be related to the dynamics of the situation. Animation such as that used in the HomeD task has been termed "stationary animation" as compared to animation that primarily involves change in the position of the objects (Harrison, 1993). In the HomeD task, transition primarily involved changing the appearance of the objects. In the B\&B task, however, transition involved changing the position of objects. Perhaps when change is integral to making a decision, gradual transition is more important than when change is incidental to selecting a decision. In the B\&B task, viewing the change in the water level was integral to choosing from among the available alternatives. In the HomeD task, however, change may have been incidental to selecting the best place to rent.

These results and the framework summarized in Figure 1 suggest a number of questions for future research. Questions regarding alterations were not considered in this study. The effects on decision quality of coloration and texturing, for example, remain to be investigated. Likewise, indirect manipulation was not a treatment level in this study. Other forms of image, transition, and interactivity also remain to be investigated. Based on the results of the study, image abstraction requires much greater attention than was given here. The results also suggest that the effects on decision quality of the relationship between the mix of animation technologies and the requirements of the task needs much more investigation. For example, it was suggested that when change is integral to making a decision, transition may be more important than when change is incidental to selecting a decision. It is expected that consideration of these and related questions would constitute a program of research.

\section{SUMMARY AND CONCLUSIONS}

It is clear that animation is becoming an increasingly popular feature in user interfaces. This paper developed the notion of animation in user interfaces designed for DSS, proposed a research framework for studying the effects of animation in user interfaces designed for DSS, and empirically tested three hypotheses derived from the framework.

Combining notions key to animation, human-computer interface, and DSS, animation in user interfaces designed for DSS was defined as images presented dynamically that change, guided by the user, in ways that improve decision quality. Animation was cited as providing the interface designer with a tool well suited to reducing the four-dimensional reality of time and three-dimensional space into the two-dimensions of the display screen. Moreover, it was suggested that the ability to effectively depict change might make animation particularly well suited to improving the decision quality of managers because so many of the decisions that managers make require identifying and assessing change, and change over time. 
Based on a review of the animation literature, simplicity, smoothness, and interactivity were defined as properties of animation in user interfaces designed for DSS. It was suggested that through the process of design, properties of image simplicity, transition and alteration smoothness, and navigation and manipulation interactivity can be specified to improve decision quality. Integrating these properties of Animation with those of User and Task, a research framework for investigating the efficacy of animation in user interfaces designed for DSS was proposed.

Testing three hypotheses derived from the proposed research framework, the effects on decision quality of different designs of image abstraction, transition, and navigation interactivity were investigated in a laboratory experiment involving two different task domains. The results indicate that animation is more than just a creative way to display a decision situation. The design of animation can affect decision quality. The results are consistent with regard to interactivity: When using animation in decision support systems, parallel navigation interactivity results in better decision quality than sequential navigation interactivity. The results regarding image abstraction and transition are not as clear. Based on the data in this study, transition effects appear to be significant when depicting dynamic, visual tasks, but they may not be as important for static, linguistic tasks. The results regarding realistic and abstract images suggest that from the perspective of improving decision quality, image abstraction is a very complex issue that perhaps needs to be considered somewhat akin to abstracting text and distinguishing information from data.

Many issues need to be investigated regarding the effective application of animation in user interfaces designed for DSS. Because so little is currently known about how to apply animation effectively in user interfaces, it is premature to make specific recommendations to the practitioner. The most robust finding of this study, however, is that the decision quality of subjects exposed to parallel navigation interactivity was greater than that of those exposed to sequential navigation interactivity. Recommendations regarding the use of image abstraction and transition effects require even more caution. Subjects using realistic images outperformed those using abstract images in one task; but in the other task, there was no difference in decision quality. Likewise, subjects exposed to gradual transition outperformed those using abrupt transition in one task; but in the other task, there was no difference in decision quality. These results might suggest that in terms of improving decision quality, realistic images should be preferred to abstract images and gradual transitions should be preferred to abrupt transitions for animation in user interfaces design for DSS. Again, these results need to be replicated in other task domains and investigated in much more detail before specific recommendations to practitioners can be made. Nevertheless, it is clear that animation in user interfaces designed for DSS can affect decision quality. This must be recognized when designing and using DSS that employ animation in the user interface.

The results of this study raise numerous research questions. Chief among these is development and validation of the notion of image abstraction as it relates to DSS in general and decision quality in particular. Investigations of alteration effects and manipulation interactivity are also indicated. The universe of discourse for interactive animation and animation in user interface design is just 
emerging, and there is a plethora of issues to be considered. The research reported here suggests that animation may provide designers of user interfaces for DSS with a tool to convert the four-dimensional reality of time and three-dimensional space into little marks on a two-dimensional screen in a way that improves decision quality. Making this conversion is a major challenge for both practitioners and researchers alike. [Received: May 8, 1996. Accepted: April 16, 1997.]

\section{REFERENCES}

Ahlberg, C., \& Shneiderman, B. (1994). Visual information seeking: Tight coupling of dynamic query filters with starfield displays. Proceedings of CHI'94. New York: ACM Press, 313-317.

American Psychological Association. (1992). Ethical principles of psychologists and code of conduct. American Psychologist, 47, 1597-1611.

Anderson, J. R. (1990). Cognitive psychology and its implications. New York: W. H. Freeman.

Badler, N. I., Phillips, C. B., \& Webber, B. L. (1993). Simulating humans: Computer graphics animation and control. New York: Oxford University Press.

Baecker, R. M., \& Small, I. (1990). Animation at the interface. In B. Laurel (Ed.), The art of human-computer interface design. Reading, MA: AddisonWesley.

Benbasat, I., \& Todd, P. (1993). An experimental investigation of interface design alternatives: Icon versus text and direct manipulation versus menus. International Journal of Man-Machine Studies, 38, 369-402.

Bertin, J. (1983). Semiology of graphics. Madison, WI: The University of Wisconsin Press.

Card, S. K., Moran, T. P., \& Newell, A. (1983). The psychology of human-computer interaction. Hillsdale, NJ: Lawrence Erlbaum Associates.

Chang, B., \& Ungar, D. (1993). Animation: From cartoons to the user interface. Proceedings of UIST '93. New York: ACM Press, 45-55.

Clanton, C., \& Young, E. (1994). Film craft in user interface design. In Tutorial Notes of CHI'94. New York: ACM Press.

Cohen, J., \& Cohen, P. C. (1975). Applied multiple regression/correlation analysis for the behavioral sciences. Hillsdale, NJ: Lawrence Erlbaum Associates.

Cremmins, E.T. (1982). The art of abstracting. Philadelphia, PA: ISI Press.

Daft, R. L. (1991). Management (2nd ed.). New York: The Dryden Press.

Davis, S. A., \& Bostrom, R. P. (1993). Training end users: An experimental investigation of the roles of the computer interface and training methods. MIS Quarterly, 17(1), 61-85.

Dent, B. D. (1985). Principles of thematic map design. Reading, MA: AddisonWesley. 
Deregowski, J. B. (1990). On two distinct and quintessential kinds of pictorial representation. In K. Landwehr (Ed.), Ecological perception research, visual communication, and aesthetics. New York: Springer-Verlag.

DeSanctis, G., \& Gallupe, R. B. (1987). A foundation for the study of group decision support systems. Management Science, 33(5), 589-609.

Erickson, D. T. (1990). Working with interface metaphors. In B. Laurel (Ed.), The art of human-computer interface design. Reading, MA: Addison-Wesley.

Espe, H. (1990). The communicative potential of pictures: Eleven theses. In K. Landwehr (Ed.), Ecological perception research, visual communication, and aesthetics. New York: Springer-Verlag.

Finkel, L. H., \& Sajda, P. (1994). Constructing visual perception. American Scientist, 82(May-June), 224-237.

Gibson, J. J. (1979). The ecological approach to visual perception. New York: Houghton Mifflin.

Gillan, D., \& Cooke, N. (1994). Methods of perceptual and cognitive research applied to interface design and testing. In Tutorial Notes of CHI'94. New York: ACM Press.

Ginzberg, M. J., \& Stohr, E. A. (1982). Decision support systems: Issues and perspectives. In M.J. Ginzberg, W. Reitman, \& E.A. Stohr (Eds.), Decision support systems. Amsterdam: North-Holland.

Gobbetti, E., Balaguer, J., \& Thalmann, D. (1993). An architecture for interaction in synthetic worlds. Proceedings of UIST '93. New York: ACM Press, 167-178.

Goldstein, B. E. (1989). Sensation and perception (3rd ed.). Belmont, CA: Wadsworth Publishing.

Gorry, G. A., \& Scott Morton, M. S. (1971). A framework for management information systems. Sloan Management Review, 13(1), 55-70.

Halas, J. (1990). The contemporary animator. Stoneham, MA: Focal Press, Butterworth-Heinemann.

Hale, D. P., \& Kasper, G. M. (1989). The effect of human-computer interchange protocol on decision performance. Journal of Management Information Systems, 6(1), 5-20.

Harrison, S. (1993). Still, animated, or nonillustrated on-line help with written or spoken instructions for performance of computer-based procedures. Doctoral dissertation, University of Minnesota, Minneapolis, MN.

Hartson, R. H., \& Hix, D. (1989). Human-computer interface development: Concepts and systems for its management. ACM Computing Survey, 2l(1), 5-92.

Henderson, J. C. (1987). Finding synergy between decision support systems and expert systems research. Decision Sciences, 18(3), 333-349.

Hix, D., \& Hartson, R. H. (1993). Developing user interfaces: Ensuring usability through product and process. New York: John Wiley \& Sons.

Hochberg, J. E. (1978). Perception (2nd ed.). Englewood Cliffs, NJ: Prentice-Hall. 
Hochberg, J. E. (1986). Visual perception of real and represented objects and events. In D.R. Gerstein \& N.J. Smelser (Eds.), Behavioral and social science: Fifty years of discovery. Washington, DC: National Academy Press.

Hochberg, J. E., \& Brooks, V. (1978). Film cutting and visual momentum. In J. W. Senders, D. F. Fisher \& R. A. Monty (Eds.), Eye movements and the higher psychological functions. Hillsdale, NJ: Lawrence Erlbaum Associates.

Hollnagel, E., \& Woods, D. D. (1983). Cognitive systems engineering: New wine in new bottles. International Journal of Man-Machine Studies, 18, 583-600.

Huber, G. P. (1983). Cognitive style as a basis for MIS and DSS design: Much ado about nothing. Management Science, 29(5), 567-579.

Humphreys, P. (1986). Intelligence in decision support. In B. Brehmer, H. Jungermann, P. Lourens \& G. Sevon (Eds), New directions in research on decision making. Amsterdam: Elsevier Science Publishers, B.V. NorthHolland.

Isdale, J. (1993). What is virtual reality? A homebrew introduction and information resource list [on-line]. October 8, Version 2.1. From ftp site ftp.u.washington.edu in public/virtual-worlds/papers as whatisvr.txt.

Jacob, R. J. K., Sibert, L. E., McFarlane, D. C., \& Mullen, M. P. (1994). Integrality and separability of input devices. ACM Transactions on Computer-Human Interaction, l(1), 3-26.

Jarvenpaa, S. L., \& Dickson, G. W. (1988). Graphics and managerial decision making: Research-based guidelines. Communications of the ACM, 31(6), 764-774.

Johnson-Laird, P. N. (1981). Mental models in cognitive science. In D.A. Norman (Ed.), Perspectives on cognitive science. Norwood, NJ: Ablex Publishing.

Just, M. A., \& Carpenter, P. (1985). Cognitive coordinate systems: Accounts of mental rotation and individual differences in spatial ability. Psychological Review, 92(2), 137-172.

Kaiser, M. K., Proffitt, D. R., Whelan, S. M., \& Hecht, H. (1992). Influence of animation on dynamical judgments. Journal of Experimental Psychology: Human Perception and Performance, 18(3), 669-690.

Kasper, G. M. (1996). A theory of decision support system design for user calibration. Information Systems Research, 7(2), 215-232.

Kaufmann, G. A. (1980). Imagery, language and cognition: Toward a theory of symbolic activity in human problem solving. Norway: Reklametrykk A.S. Universitetsforlaget (printed in North America by Columbia University Press, NY).

Kaufmann, G. A. (1985). Theory of symbolic representation in problem solving. Journal of Mental Imagery, 9(2), 51-70.

Keen, P. G. W. (1987). Decision support systems: The next decade. Decision Support Systems, 3, 253-265.

Keen, P. G. W., \& Scott Morton, M. S. (1978). Decision support systems: An organizational perspective. Reading, MA: Addison-Wesley. 
Keller, P. R., \& Keller, M. M. (1993). Visual cues. Los Alamitos, CA: IEEE Computer Society Press and IEEE Press.

Kosslyn, S. M. (1985). Graphics and human information processing. Journal of the American Statistical Association, 80(391), 499-512.

Krampen, M. (1990). Functional versus dysfunctional aspects of information surfaces. In K. Landwehr (Ed.), Ecological perception research, visual communication, and aesthetics. New York: Springer-Verlag.

Luconi, F. L., Malone, T. W., \& Scott Morton, M. S. (1986). Expert systems: The next challenge for managers. Sloan Management Review, 27(4), 3-14.

MacLeod, C. M., Hunt, E. B., \& Matthews, N. N. (1978). Individual differences in the verification of sentence-picture relationships. Journal of Verbal Learning and Verbal Behavior, 17, 493-507.

Magnenat-Thalmann, N., \& Thalmann, D. (1985). Computer animation: Theory and practice. New York: Springer-Verlag.

Marks, D. F. (1973). Visual imagery differences in the recall of pictures. British Journal of Psychology, 64(1), 17-24.

Marks, D. F. (1989). Bibliography of research utilizing the vividness of visual imagery questionnaire. Perception and Motor Skills, 69, 707-718.

Marr, D. (1982). Vision: A computational investigation into the human representation and processing of visual information. San Francisco, CA: W.H. Freeman \& Co.

Mason, R. O., \& Mitroff, I. A. (1973). A program for research on management information systems. Management Science, 19(5), 475-487.

Mennecke, B. E., \& Wheeler, B. C. (1995). An essay and resource guide for dyadic and group task selection and usage [on-line]. http://www.bmgt.umd.edu/ business/academicdepts/IS/tasks/essay.html.

Newell, A., \& Simon, H. A. (1972). Human problem solving. Englewood Cliffs, NJ: Prentice-Hall.

Newell, A., \& Simon, H. A. (1976). Computer science as empirical inquiry: Symbols and search. Communications of the ACM, 19(3), 113-126.

Nielsen, J. (1993). Usability engineering. San Diego, CA: Academic Press.

Norman, D. A. (1986). Cognitive engineering. In D.A. Norman \& S.W. Draper (Eds.), User-centered system design: New perspectives on human-computer interaction. Hillsdale, NJ: Laurence Erlbaum Associates.

Olson, G. M., \& Olson, J. S. (1991). User-centered design of collaborative technology. Organizational Computing, 1(1), 61-83.

Outside In. (1994). Geometry Center, University of Minnesota, In SIGGRAPH 94: Electronic Theater. ACM SIGGRAPH Video Review, Issue 101, ACM, New York.

Paivio, A. (1971). Imagery and verbal processes. New York: Holt, Rinehart and Winston. 
Palmiter, S. (1993). The effectiveness of animated demonstrations for computerbased tasks: A summary, model and future research. Journal of Visual Languages and Computing, 4, 71-89.

Palmiter, S., Elkerton, J., \& Baggett, P. (1991). Animated demonstrations vs written instructions for learning procedural tasks: A preliminary investigation. International Journal of Man-Machine Studies, 34, 687-701.

Park, O., \& Hopkins, R. (1992). Instructional conditions for using dynamic visual displays: A review. Instructional Science, 21(6), 427-449.

Payne, J. W. (1982). Contingent decision behavior. Psychological Bulletin, 92(2), $382-402$.

Remus, W. E., \& Kotteman, J. (1986). Toward intelligent decision support systems: An artificially intelligent statistician. MIS Quarterly, 10(4), 403-418.

Richardson, A. (1994). Individual differences in imaging: Their measurement, origins, and consequences. Amityville, NY: Baywood.

Rieber, L. P., Boyce, M. J., \& Assad, C. (1990). The effects of computer animation on adult learning and retrieval tasks. Journal of Computer-Based Instruction, 17(2), 46-52.

Rieber, L. P., \& Hannafin, M. J. (1988). Effects of textual and animated orienting activities and practice on learning from computer-based instruction. Computers in the Schools, 5(1\&2), 77-89

Robertson, G. G., Card, S. K., \& Mackinlay, J. D. (1989). The cognitive coprocessor architecture for interactive user interfaces. Proceedings of UIST '89. New York: ACM Press, 10-18.

Robertson, G. G., Card, S. K., \& Mackinlay, J. D. (1993). Information visualization using 3D interactive animation. Communications of the $A C M, 36(4), 57-71$.

Rouse, W. B., \& Morris, N. M. (1986). On looking into the black box: Prospects and limits in the search for mental models. Psychological Bulletin, 100(3), 349-363.

Scott Morton, M. S. (1984). The state of the art of research. In F.W. McFarlan (Ed.), The information systems research challenge. Cambridge, MA: Harvard Business School Press.

Shneiderman, B. (1992). Designing the user interface: Strategies for effective human-computer interaction (2nd ed.). Reading, MA: Addison-Wesley.

SIGGRAPH 94: Electronic Theater. (1994). ACM SIGGRAPH Video Review, Issue 101, ACM, New York.

Simon, H. A. (1960). The new science of management decision. New York: Harper \& Row.

Simon, H. A. (1975). The functional equivalence of problem solving skills. Cognitive Psychology, 36(7), 268-289.

Solomon, C. (1983). The computer Kodak animation book. Rochester, NY: Eastman Kodak Company. 
Sperling, G., \& Dosher, B. (1986). Strategy and optimization in human information processing. In K. R. Boff, L. Kaufman \& J. P. Thomas (Eds.), Handbook of perception and human performance. San Diego, CA: Academic Press.

Sprague, R. H., \& Carlson, E. D. (1982). Building effective decision support systems. Englewood Cliffs, NJ: Prentice-Hall.

Stasko, J. T. (1993). Animation in user interfaces: Principles and techniques. In L. Bass \& D. Prasun (Eds.), User interface software. New York: John Wiley.

Thuring, M., Hannemann, J., \& Haake, J. M. (1995). Hypermedia and cognition: Designing for comprehension. Communications of the ACM, 38(8), 57-66.

Todd, P. A., \& Benbasat, I. (1994a). The influence of decision aids on choice strategies: An experimental analysis of the role of cognitive effort. Organizational Behavior and Human Decision Processes, 60, 36-74.

Todd, P. A., \& Benbasat, I. (1994b). The influence of decision aids on choice strategies under conditions of high cognitive load. IEEE Transactions on Systems, Man, and Cybernetics, 24(4), 537-547.

Treisman, A., \& Souther, J. (1985). Search asymmetry: A diagnostic for preattentive processing of separable features. Journal of Experimental Psychology, 114(3), 285-310.

Tufte, E. R. (1990). Envisioning information. Cheshire, CT: Graphic Press.

Vaananen, K., \& Shmidt, J. (1994). User interfaces for hypermedia: How to find good metaphors? Proceedings of CHI'94. New York: ACM Press, 263-264.

Walls, J. G., Widmeyer, G. R., \& El Sawy, O. A. (1992). Building an information design theory for vigilant EIS. Information Systems Research, 3(1), 36-59.

The Wall Street Journal. (1996, December 9). Teen math whizzes go Euclid one better. B1.

Wickens, C. D. (1987). Information processing, decision making, and cognition. In The handbook of human factors. New York: John Wiley \& Sons, 73-101.

Wickens, C. D. (1992). Engineering psychology and human performance. New York: Harper Collins.

Winer, B. J. (1971). Statistical principles in experimental design. New York: McGraw-Hill.

Woods, D. D. (1984). Visual momentum: A concept to improve the cognitive coupling of person and computer. International Journal of Man-Machine Studies, 21, 229-244.

Cleotilde González received a $\mathrm{Ph} . \mathrm{D}$. in management information systems from Texas Tech University. She is currently a postdoctoral research associate at Carnegie Mellon University. Dr. González is an associate professor in the Department of Computer Engineering at Universidad de las Américas Puebla, México, where she is instrumental in the Laboratory of Interactive and Cooperative Technologies. Her research interests are in animation, graphical and spatial 
representation of data, usability testing, and design of the user interface for supporting decision making.

George M. Kasper is a professor and chair of the Department of Information Systems in the School of Business at Virginia Commonwealth University. Prior to this position, he was a professor of information systems at Texas Tech University. His research in decision support systems and user interface design has been published in many journals. Professor Kasper also serves as chair of the Special Interest Group on Management Information Systems (SIGMIS) of the ACM. 